\title{
Totally impermeable film (TIF) reduces emissions in perennial crop fumigation
}

by Suduan Gao, Bradley D. Hanson, Ruijun Qin, Jose Cabrera, James S. Gerik, Dong Wang and Greg T. Browne

\section{Many perennial nursery fields and} replanted orchards and vineyards in California are treated with preplant soil fumigants to control soilborne pests. In annual crops, such as strawberry, covering fumigated fields with totally impermeable film (TIF) has shown promise in controlling emissions and improving fumigant distribution in soil. The objective of this research was to optimize the use of TIF for perennial crops via three field trials. TIF reduced peak emission flux and cumulative emissions by $>90 \%$ relative to polyethylene tarp during a 2-week covering period. After the TIF was cut, emissions were greatly reduced compared to when tarps were cut after 6 days. TIF maintained higher fumigant concentrations under tarp and in the soil than polyethylene film. The results indicate that TIF can increase fumigation efficiency for perennial crop growers.

\footnotetext{
Tn California, successful orchard replantling in many situations still depends
} on soil fumigation to control soilborne pests. Additionally, producing perennial tree and grapevine nursery stock that is free of plant-parasitic nematodes (to meet regulations [CDFA 2008]) is achieved primarily by growing the stock in open fields treated with preplant soil fumigation. The most effective fumigant, methyl bromide, was phased out in January 2005, although some uses are currently allowed under critical use exemptions (CUEs) and as treatments for meeting quarantine and preshipment (QPS) criteria. Many perennial crop growers have adopted methyl bromide alternatives such as 1,3-dichloropropene (1,3-D) and chloropicrin. These alternatives, however, are also highly regulated because of their toxicity and the

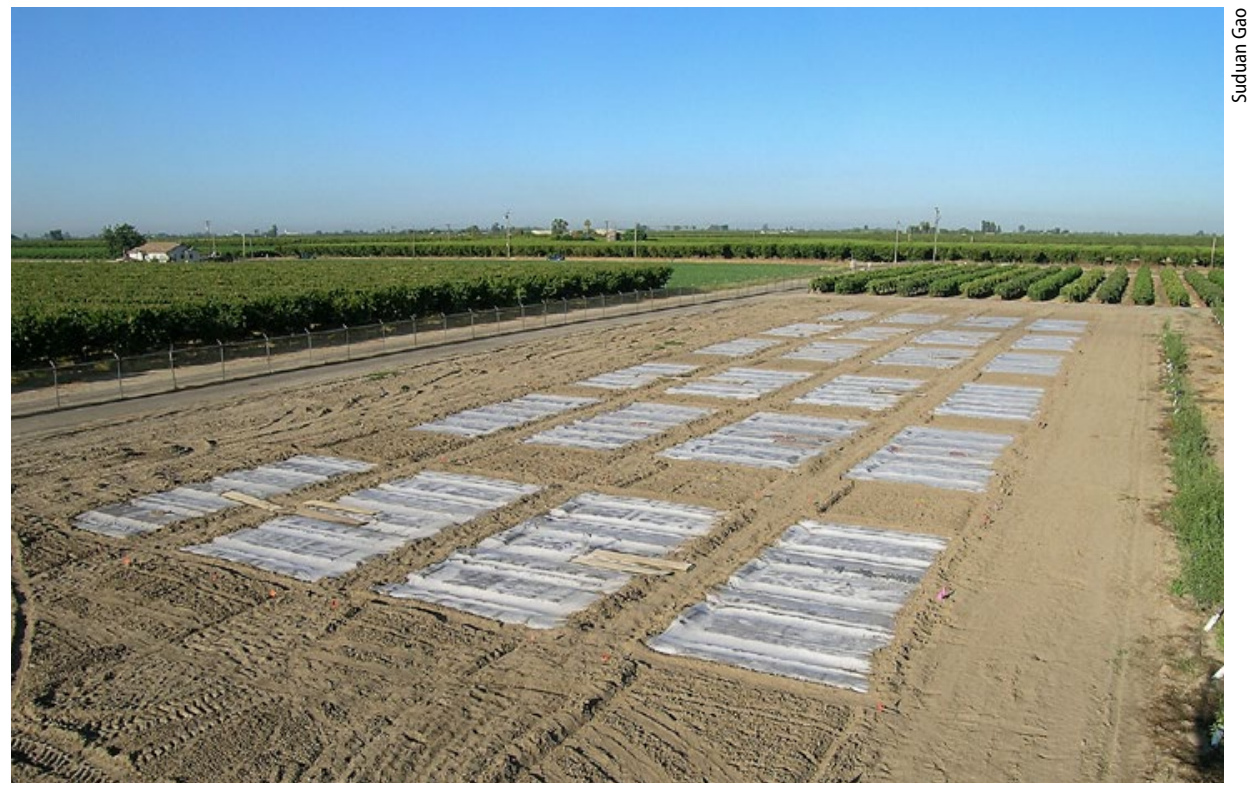

Data from three field trials conducted near Parlier, above, show that totally impermeable film (TIF) maintained higher fumigant concentrations under tarp and in the soil than polyethylene film.

emission of volatile organic compounds (VOCs), which degrade air quality by forming ground-level ozone.

Controlling emissions from soil fumigation can help maintain the availability of fumigants to growers, and it is required by environmental regulations in ozone non-attainment areas such as the San Joaquin Valley (CDPR 2009; US EPA 2009). Research in reducing emissions from soil fumigation of perennial crops has been supported by the USDA-ARS Pacific Area-Wide Pest Management Program for Integrated Methyl Bromide Alternatives. Phase I of the research (2006-2008) evaluated plastic tarping and surface treatments with water, organic amendments and chemicals. Low-permeability tarps demonstrated significant emission reductions, while the irrigation, organic matter and chemical treatments tended to sacrifice efficacy near the soil surface because of the reduced fumigant concentrations there; the findings have been summarized in Gao et al. (2011), Hanson et al. (2013) and Jhala et al. (2012). Phase II (2009-2010) focused on developing fumigation methods using low-permeability tarps, including totally impermeable film (TIF), and we report those results here.

Low-permeability films, such as TIF (Chow 2008), have been shown to effectively control emissions and improve fumigation efficacy in annual crops such as strawberry by retaining higher fumigant concentrations and creating a more uniform distribution of fumigant in the soil profile compared to standard polyethylene tarp (Qin et al. 2011). However, the benefits of TIF for soil fumigation in perennial crops have not been evaluated.

During 2009 and 2010, we conducted field trials to address how to use TIF efficiently in perennial orchards, vineyards and nurseries. Although tarps have not typically been used for replanted orchards, TIF may improve efficacy and allow the use of reduced fumigant rates. Our research objective was to optimize the use of TIF to reduce emissions, improve efficacy and potentially reduce fumigant application rates. This research was also conducted to determine how to avoid the surge of emissions that had been observed when TIF was cut after 6 days, the cutting time that is commonly used for standard polyethylene film (Qin et al. 2011). This paper includes our research data for fumigant concentration in the air under the tarps (above soil

Online: http://californiaagriculture.ucanr.edu/ landingpage.cfm?article =ca.v067n04p217\&fulltext=yes doi: 10.3733/ca.v067n04p217 
surface), emission flux during tarp covering and after tarp cutting, cumulative fumigant emissions, fumigant gas concentration in the soil profile, and residual fumigants. Detailed efficacy data are reported in Cabrera et al. (2011).

\section{Three field trials}

Three field trials were conducted between October 2009 and October 2010 at the USDA-ARS San Joaquin Valley Agricultural Science Center, near Parlier. The plots had previously been planted with a vineyard, and the soil was a Hanford sandy loam (coarse-loamy, mixed, superactive, nonacid, thermic Typic Xerorthents). For all three trials, Telone C35 (a mixture of 1,3-D 61\% and chloropicrin $35 \%$, weight per weight [w/w]) was shank applied at an 18-inch depth with a 20-inch shank spacing using a commercial Telone shank applicator. Three replications were conducted for each treatment.

The TIF (VaporSafe, 1-mil thickness, clear, Raven Industries, Sioux Falls, SD) was 10.5 feet wide for the first trial (the first time it was available for field testing) and 13 feet wide for the other two trials. In the first trial, two sheets of TIF were joined by gluing and applied to a 20-foot-wide plot; a single sheet was applied to a 12-foot-wide plot for the second trial; and three sheets were applied to a 36-foot-wide plot for the third trial. These corresponded to fumigant application passes of two, one and three (representing the width of treatment plot) for the first, second and third trials, respectively. The polyethylene film (1-mil thickness and 13-foot width) was provided by Trical, Inc. (Hollister, CA) and applied in a single sheet for the first two trials and three sheets joined in a plot for the third trial.

For all three trials, soil was cultivated and irrigated before fumigation to produce soil moisture conditions that met Telone C35 label requirements. Soil water content profiles were similar in the fall trials, but with a slightly drier surface in the fall 2010 trial (fig. 1). The soil in the summer 2010 field trial had higher water content. According to CIMIS data (Station 39 , at Parlier), soil temperatures averaged $63.6^{\circ} \mathrm{F}, 73.9^{\circ} \mathrm{F}$ and $72.8^{\circ} \mathrm{F}$ during the fall 2009, summer 2010 and fall 2010 field trials, respectively. For all trials, sampling procedures in the field, sample processing and laboratory analyses followed established procedures as described in Gao et al. (2009).

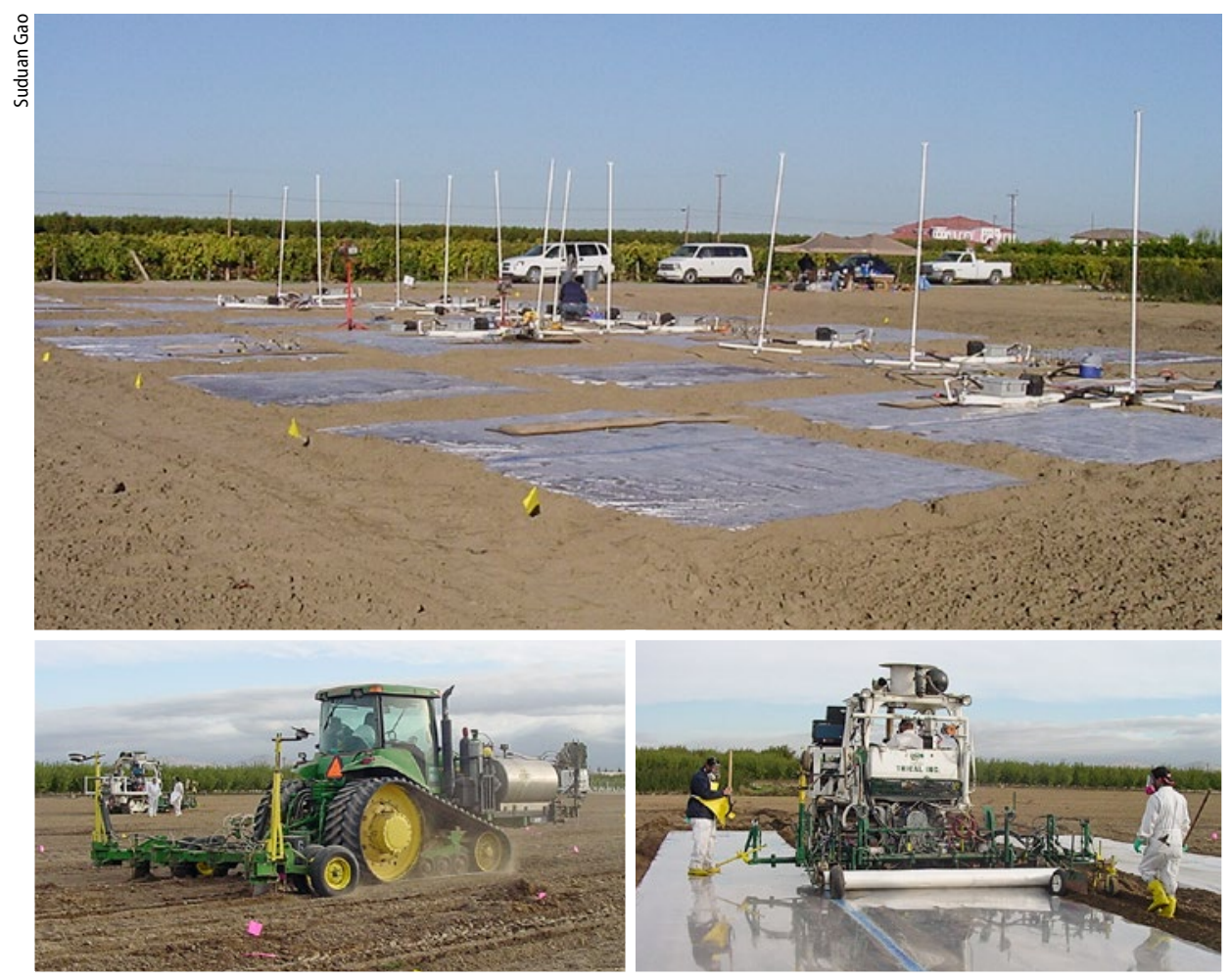

Researchers used dynamic flux chamber equipment, top, to measure fumigant emissions throughout the fall 2009 trial period and 24 hours after tarp cutting. Bottom left, fumigant injection; bottom right, plastic tarp installment at Parlier, Fresno County.

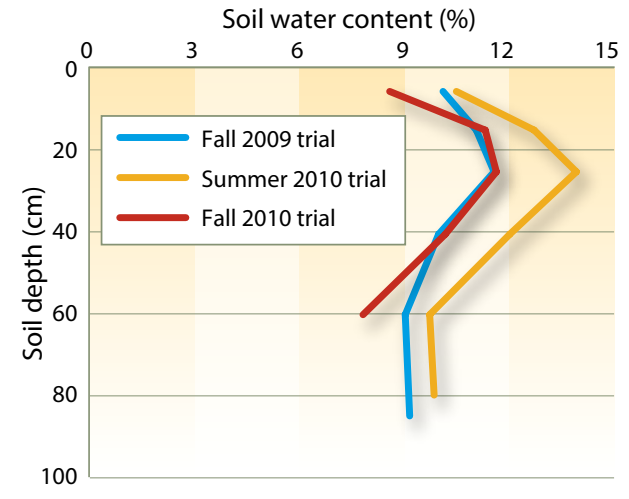

Fig. 1. Soil water content 1 day before fumigant application in the three field trials. Plotted are averages of three location measurements across the field. Error bars are omitted for readability.

A summary of the field trials is provided in table 1 . The fall 2009 trial was designed to evaluate fumigant emission, distribution and efficacy from three Telone C35 rates (full rate: 100\% of the maximum label rate, which is 48 gallons, or 540 pounds, per acre; $75 \%$ of full rate [0.75]; and 50\% of full rate [0.5]) plus a nonfumigated control and two types of plastic tarps, standard polyethylene and TIF. Measurements were made of fumigant concentration changes in the air under the tarp, emission flux during tarp covering and after tarp cutting, and residual fumigants in the soil at the end of the trial. Fumigant emissions throughout the first trial period ( 2 weeks) and 24 hours after tarp cutting were measured using dynamic flux chambers (Gao et al. 2008; Gao and Wang 2011). Malfunctions of the fumigant application equipment resulted in an overapplication of the 0.75 rate, resulting in an actual rate similar to the full rate. Due to application rig emitter clogging problems, the calculation of total emission loss as a percentage of total amount applied could not be performed; thus, relative emissions and differences between treatments, rather than absolute values, are presented.

The summer 2010 trial was conducted on the same soil as the fall 2009 trial. Fumigant distribution in the soil profile and concentration in the air under the TIF tarp at the full and 0.5 rates were monitored and compared with data from the plots with standard polyethylene tarp and a full-rate application.

The fall 2010 trial focused on fumigation efficacy and correlation with fumigant concentration and time (CT) exposure index values, and tested full, 
0.5 and 0.25 fumigation application rates under polyethylene and TIF tarps, as well as nonfumigated controls. Fumigant concentrations in the air under the tarp and in the soil profile (soil-gas phase) were monitored.

\section{Fumigant in air under tarp}

High fumigant concentrations in the air under the tarp benefit pest control near the soil surface but can cause an emissions surge at tarp cutting, which risks workers' and bystanders' safety. 1,3-D concentrations measured during the fall trials immediately under the tarp are shown in figure 2. Chloropicrin concentrations (data not shown) followed a similar pattern but were substantially lower than 1,3-D because the initial application rate was lower and the half-life of chloropicrin in soil is generally much shorter than that of 1,3-D.

During the fall 2009 trial, 1,3-D concentration was up to three times higher under TIF than under standard polyethylene film at the full application rate (fig. 2A). At the half rate, 1,3-D concentration under TIF was similar to or even higher than at the full rate under polyethylene film. Prior to tarp cutting, the average 1,3-D concentration at the full rate was $0.6 \mu \mathrm{g}$ $\mathrm{cm}^{-3}$ under the TIF tarp compared with only $0.2 \mu \mathrm{g} \mathrm{cm}^{-3}$ under the polyethylene tarp.

Similarly, during the summer 2010 field trial, the average of 12 under-tarp air samples 1 week after fumigant application showed a higher 1,3-D concentration at the half rate under TIF than at the full rate under polyethylene film (data not shown).

Concentrations of 1,3-D under the tarps during the fall 2010 trial (fig. 2B) were again the highest under TIF at the full rate, and few differences were observed among the 0.5 rate under TIF and the full rate under polyethylene, with the 0.25 rate under TIF (data not shown) showing slightly lower 1,3-D concentrations than the 0.5 rate under TIF.

The under-tarp concentrations of 1,3-D were much higher for the fall 2010 trial (fig. 2B) than for the other two trials, especially in the first few days after application. And, in that trial, the concentrations increased faster initially and dropped more rapidly with time. This was most likely due to temperature differences: soil was warmer in September 2010 than in October and November 2009; soil

TABLE 1. Summary of the treatments and emissions monitoring in three field trials

\begin{tabular}{|c|c|c|}
\hline Field trial & $\begin{array}{l}\text { Treatment } \\
\text { (shank injection of Telone C35) }\end{array}$ & Field measurement \\
\hline $\begin{array}{l}\text { Fall } 2009 \\
\text { (Oct 27-Nov 9) }\end{array}$ & $\begin{array}{l}\text { Rate: full rate ( } 48 \text { gallon/acre, the } \\
\text { maximum label rate), } 0.75^{*} \text { and } 0.5 \text { of } \\
\text { the full rate, nonfumigated control } \\
\text { Tarp: standard polyethylene, TIF }\end{array}$ & $\begin{array}{l}\text { Fumigant concentrations in air under tarp } \\
\text { Emission flux after tarp cutting } \\
\text { Residual fumigants }\end{array}$ \\
\hline $\begin{array}{l}\text { Summer } 2010 \\
\text { (Jun 9-Jul 1) }\end{array}$ & $\begin{array}{l}\text { Rate and tarp: full rate, } 0.5 \text { of the full } \\
\text { rate under TIF, full rate under standard } \\
\text { polyethylene film }\end{array}$ & $\begin{array}{l}\text { Fumigant concentrations in air under tarp } \\
\text { Fumigant distribution in soil }\end{array}$ \\
\hline $\begin{array}{l}\text { Fall } 2010 \\
\text { (Sep 8-Oct 13) }\end{array}$ & $\begin{array}{l}\text { Rate: full rate, } 0.5 \text { and } 0.25 \text { of the full rate, } \\
\text { nonfumigated control } \\
\text { Tarp: standard polyethylene, TIF }\end{array}$ & $\begin{array}{l}\text { Fumigant concentrations in air under tarp } \\
\text { Fumigant distribution in soil }\end{array}$ \\
\hline
\end{tabular}
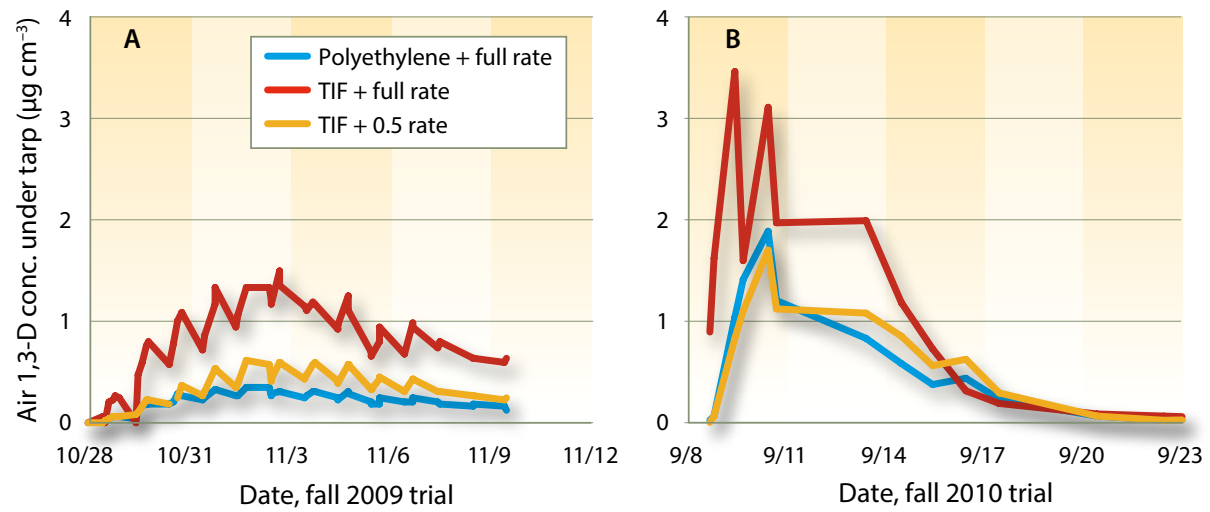

Fig. 2. Fumigant concentration changes in air under the tarp. In the fall 2010 trial, the 0.25 rate under TIF (not plotted) had slightly lower 1,3-D concentrations than the 0.5 rate under TIF. Plotted are averages of three replicates.

moisture conditions were similar except that the soil surface and deeper layers were drier in the fall 2010 trial (fig. 1). The higher temperature in fall 2010 may have resulted in greater volatilization of the fumigants from the soil to the headspace under the tarp, followed by a drop in concentrations due to greater degradation of the fumigants in the warmer soils. fumigants under TIF had dissipated after 2 weeks in summer 2010. These data demonstrate that high temperatures enhanced fumigant dissipation and degradation.

The air under tarp data suggest that using TIF tarp in early fall may have the advantage over using it in summer and late fall by maintaining higher fumigant concentrations in soil following fumiga-

\section{The data suggest that using TIF tarp in early fall may have the advantage over using it in summer and late fall.}

Data from the summer 2010 trial (collected in June, when temperatures were the highest among the three trials) showed concentrations just one-third of the concentrations in the fall 2009 trial 1 week after application of the same rate, possibly due to faster dissipation of fumigation at high temperatures (data not shown). Higher amounts of fumigants under TIF were observed after the 2-week tarp covering in fall 2009 than under polyethylene (fig. 2A), but most of the tion. The tarp was cut after 2 weeks, when very low fumigant concentrations $(<0.01$ $\mu \mathrm{g} \mathrm{cm}^{-3}$ ) were monitored under the tarp in the fall 2009 trial, indicating a low risk of an emissions surge.

\section{Flux and cumulative emissions}

TIF reduced both emission flux and cumulative loss by $>90 \%$ compared to standard polyethylene tarp during the 2-week tarp-covering period (figs. 3 and 4) in the fall 2009 trial. However, emissions 


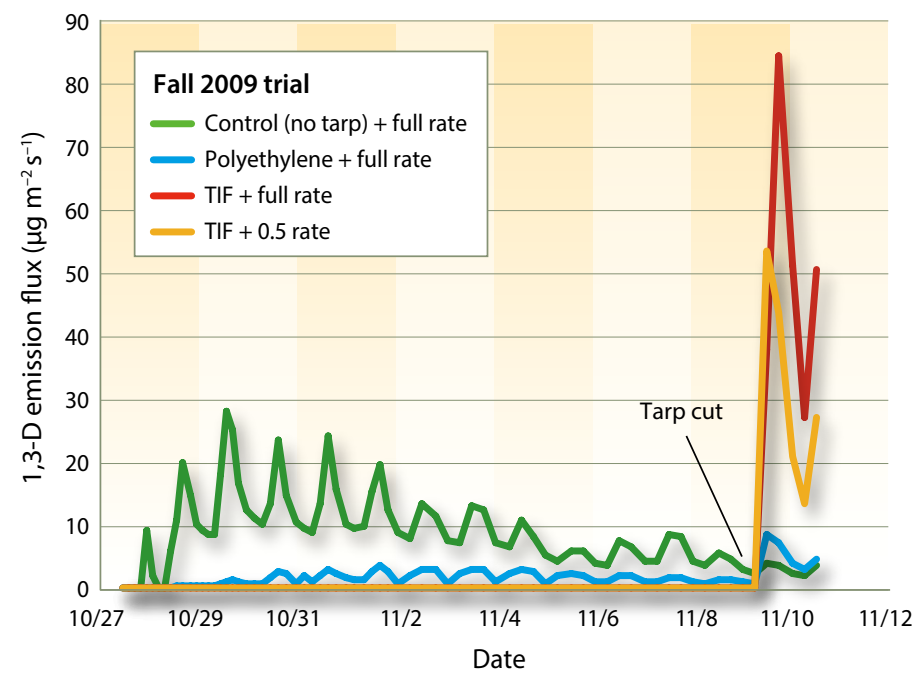

Fig. 3. Emission flux of 1,3-D in the fall 2009 field trial. Plotted are averages of three replicates.

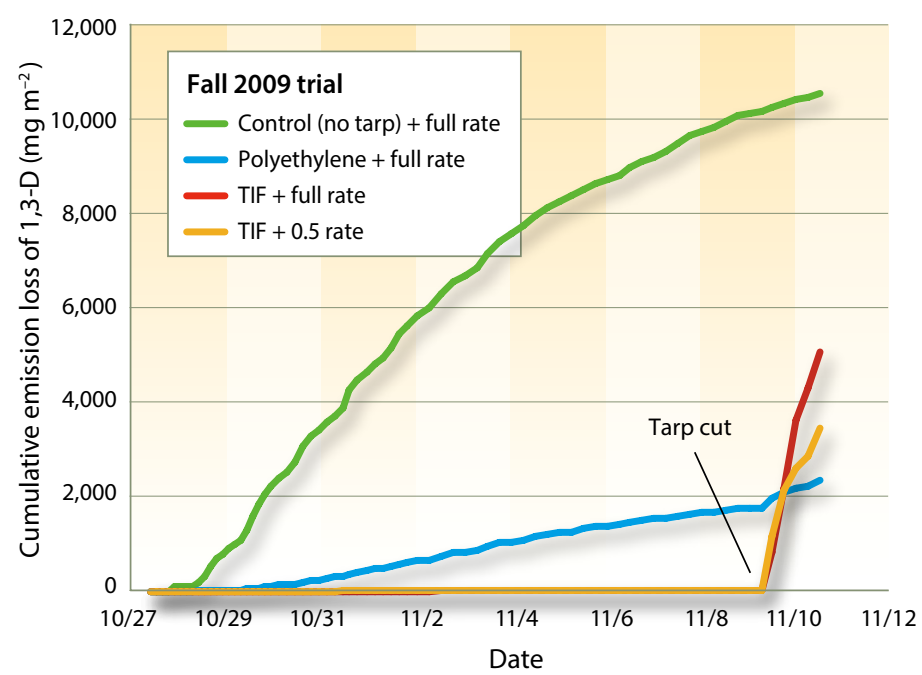

Fig. 4. Cumulative emission loss of 1,3-D in the fall 2009 field trial. Plotted are averages of three replicates. still surged following tarp cutting with much higher emission rates from TIF plots than from the polyethylene plots due to the higher concentrations of fumigant remaining under the tarp (fig. 2A). The flux values after tarp cutting (13 days after application) in the fall 2009 trial were substantially lower than those reported (over $200 \mu \mathrm{g} \mathrm{m}^{-2} \mathrm{~s}^{-1}$ ) when tarp cutting occurred 6 days after fumigant application (Qin et al. 2011). Emissions of chloropicrin were lower than 1,3-D emissions (data not shown) because of the lower amount of chloropicrin applied and its faster degradation; following an application of Telone C35, it's 1,3-D that is the major concern for worker safety in an emissions surge.

Total fumigant emission loss from the field is also a concern because VOCs degrade air quality. The total loss includes loss during the tarp-covering period and loss after tarp cutting. Figure 4 shows that during tarp covering, total emissions from the TIF plots were extremely low, but emissions spiked at tarp cutting, resulting in cumulative emissions that were higher than those from the plots with polyethylene tarp. The 0.5 rate applied under TIF resulted in lower emissions than the full rate. Total emissions following tarp cutting could have been greater than reported in figure 4 because monitoring was done for only about 24 hours after tarp cutting.

\section{Fumigant distribution in soil}

In the summer 2010 trial, fumigant distribution was monitored by measuring gas fumigant concentration changes over time in the soil profile. Fumigant concentration in the soil-gas phase was not significantly different between the TIF and polyethylene film treatments at the same application rate (data not shown). It is possible that the high soil temperature in the summer caused fast dispersion of fumigants in the soil and also possibly from the soil at the edges of the single strip of tarp. In the fall 2010 trial, soil-gas concentrations between the injection lines at the center of the three sheets that covered the plots were monitored, and the averaged data are shown in figure 5.

The TIF full-rate treatment resulted in generally higher 1,3-D concentrations throughout the soil profile than were found in the polyethylene full-rate plots, at various sampling times (fig. 5). The highest 1,3-D concentrations measured for the TIF full-rate, polyethylene full-rate, TIF 0.5 rate and TIF 0.25 rate treatments were 17.4, 12.2, 5.5 and $3.8 \mu \mathrm{g}$ $\mathrm{cm}^{-3}$, respectively, as determined at 55 centimeters depth and 24 hours following fumigant application. The data indicate that although TIF may increase fumigant concentration and improve fumigant distribution in perennial crop fields, it is not as effective as it is with annual crops, which usually require shallower injections than perennials (Qin et al. 2011).

\section{Residual fumigant}

TIF increased fumigant residence time in soil based on measurement of soil samples collected at the end of the fall 2009 trial, 2 weeks after fumigant application (fig. 6). The highest residual 1,3-D concentration in the soil was from the TIF full-rate treatment followed by the polyethylene full-rate, the control (no tarp) full-rate, and the TIF half-rate treatments. TIF also increased residual chloropicrin in soil, but the concentration was generally an order of magnitude lower than that of 1,3-D.

The increased residual fumigant under TIF provides the source of emissions after tarp cutting. In cool temperatures, TIF may need to be left in place longer to allow the fumigant to degrade and reduce the emissions surge. If residual fumigant concentrations are high after tarp cutting, planting time may need to be delayed to avoid phytotoxicity to roots.

\section{Industry benefits}

TIF can substantially reduce fumigant emissions by retaining fumigants under the tarp. However, to allow for fumigant degradation and avoid significant emission surges at tarp cutting, TIF needs to remain in the field for longer than polyethylene tarp, especially during periods of lower temperature such as late fall. When temperatures are high, 2 weeks of TIF tarp covering may be sufficient without high risk of exposure at tarp cutting. When temperatures are cool, more than 2 weeks of tarp covering may be needed.

All of our fumigant-monitoring data support that TIF can effectively increase fumigant concentration under the tarp and potentially increase fumigant residence times in the soil profile compared to polyethylene film when fumigants are shank applied at 18 inches depth. The 
increased and prolonged concentrations offer better pest control per amount of fumigant applied. Efficacy data reported in Cabrera et al. (2011) indicate there is potential for using reduced rates under TIF. TIF tarps are more expensive than standard polyethylene tarps, but the extra cost might be offset by savings from reduced fumigant application rates. The net cost will need to be determined.

\section{S. Gao is Research Soil Scientist, Water} Management Research Unit (WMRU), US Department of Agriculture Agricultural Research Service (USDA-ARS), Parlier; B.D. Hanson is UC Cooperative Extension Specialist, Department of Plant Sciences, UC Davis; R. Qin is Project Specialist, Department of Plant Sciences, UC Davis; J. Cabrera is Research Scientist, Bayer CropScience, Fresno; J.S. Gerik is Research Plant Pathologist, WMRU, USDA-ARS, Parlier; D. Wang is Research Leader, WMRU, USDA-ARS, Parlier; and G.T. Browne is Project Coordinator, USDA-ARS Pacific Area-Wide Pest Management Program, UC Davis.

Funding support for this research was provided by USDA-ARS Pacific Area-Wide Pest Management Program for Integrated Methyl Bromide Alternatives and the Almond Board of California. Fumigant and fumigation service for all trials were provided by Trical, Inc. Personnel supporting this research include Robert Shenk, Allison Kenyon, Aileen Hendratna, Tom Pflaum, Jim Gartung, Stella Zambrzuski, Matt Gonzales and Patricia Mungur in the WMRU, and Carl Hawk with his field crew in USDA-ARS, Parlier.

\section{References}

Cabrera JA, Hanson BD, Abit MJM, et al. 2011. Efficacy of 1,3-dichloropropene plus chloropicrin reduced rates under two different tarps against nematodes, pathogens and weeds. In: Proc Ann Int Res Conf on MeBr Alternatives and Emission Reductions, San Diego, CA, Oct. 30-Nov. 2, 2011. p 75-1 to 75-3. www.mbao.org/2011/ Proceedings/75CabreraA.pdf.

[CDFA] California Department of Food and Agriculture 2008. Nursery Inspection Procedures Manual (NIPM) Guidelines. www.cdfa.ca.gov/plant/pe/Nursery/NIPM. html.

[CDPR] California Department of Pesticide Regulation. 2009. Volatile Organic Compound (VOC) Emissions from Pesticides. www.cdpr.ca.gov/docs/emon/vocs/vocproj/ vocmenu.htm.

Chow E. 2008. Properties of EVOH and TIF films for the reduction of fumigant dosage and VOC emission. In: Proc Ann Int Res Conf on MeBr Alternatives and Emission Reductions, Orlando, FL, Nov. 11-14, 2008. p 38 (1). www. mbao.org/2008/Proceedings/038ChowEMBAO2008Ku raray.pdf.

Gao S, Hanson BD, Wang D, et al. 2011. Methods evaluated to minimize emissions from preplant soil fumigation. Calif Agr 65(1):41-6.

Average 1,3-D soil gas concentration $\left(\mu \mathrm{g} \mathrm{cm}^{-3}\right)$

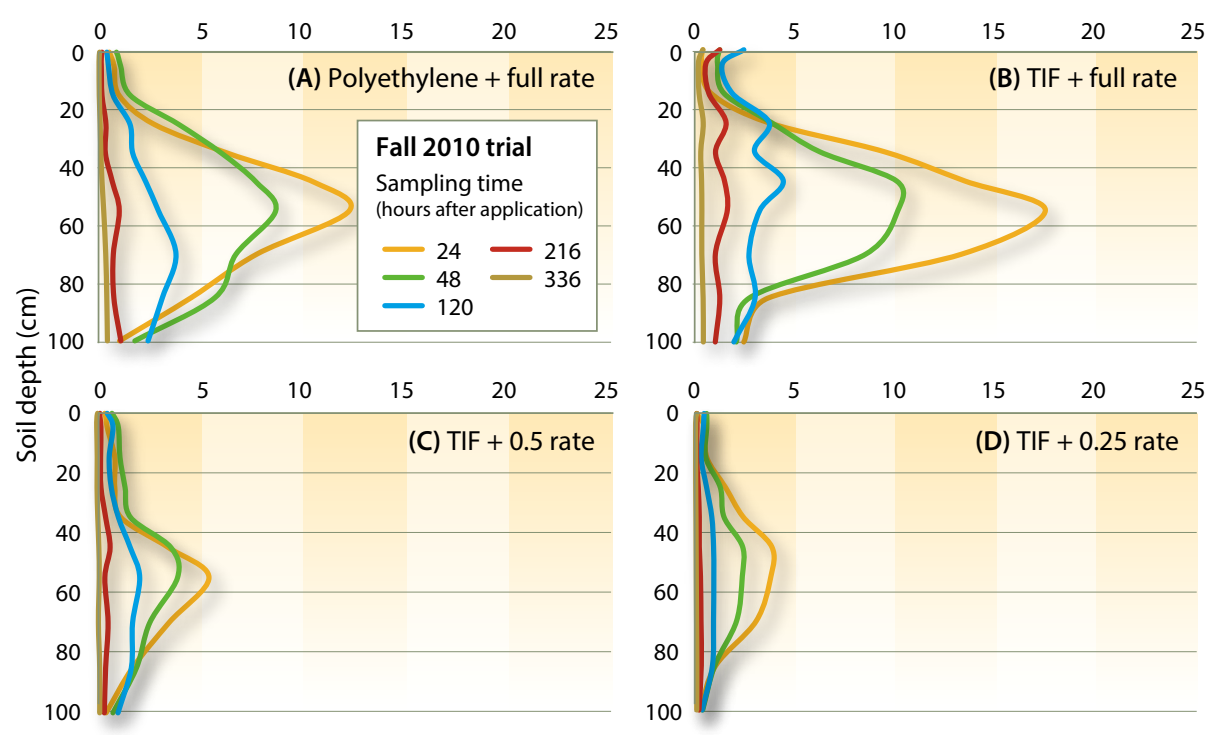

Fig. 5. Changes in 1,3-D concentration in the soil-gas phase, in the fall 2010 trial. Plotted are averages of three replicates. Soil depth is in centimeters ( $1 \mathrm{inch}=2.54$ centimeters).
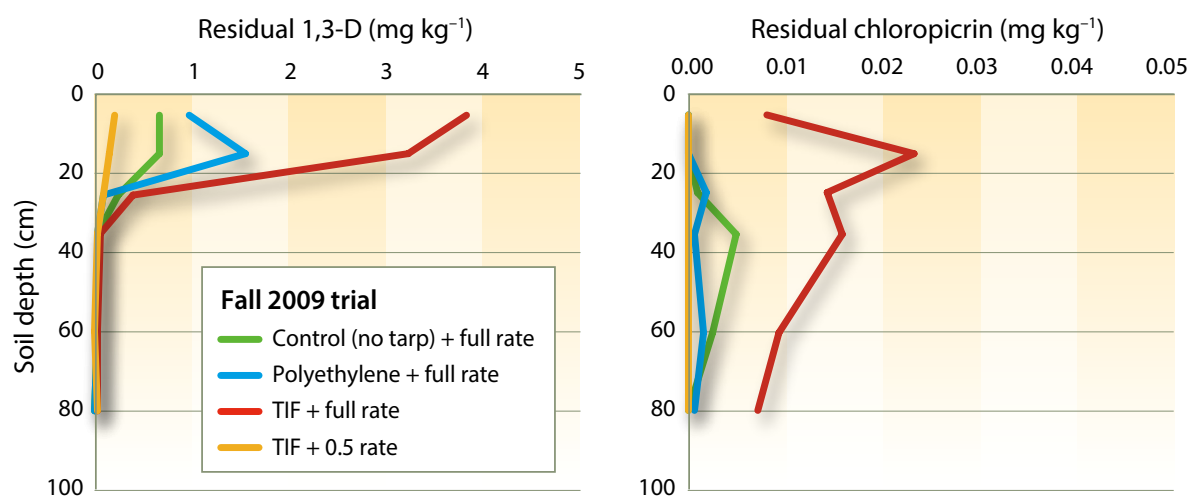

Fig. 6. Residual soil fumigants (1,3-D and chloropicrin) 14 days after fumigant application in the fall 2009 trial. Plotted are averages of three replicates. Soil depth is in centimeters ( 1 inch $=2.54$ centimeters).

Gao S, Qin R, Hanson BD, et al. 2009. Effects of manure and water applications on 1,3-dichloropropene and chloropicrin emission in a field trial. J Agr Food Chem 57:5428-34.

Gao S, Wang D. 2011. Chapter 9: Vapor flux measurements - chamber methods. In: Saponaro S, Sezenna E, Bonomo L (eds.). Vapor Emission to Outdoor Air and Enclosed Spaces for Human Health Risk Assessment: Site Characterization, Monitoring and Modeling. Hauppauge NY: Nova Science Publishers. p 191-207.

Gao S, Wang D, Pflaum T, et al. 2008. Dynamic flux chamber systems for fumigant emission measurements. Ann Int Res Conf on MeBr Alternatives and Emission Reductions, Orlando, FL, Nov. 11-14, 2008. p 21-1 to 21-4. www. mbao.org/2008/Proceedings/mbrpro08.html.

Hanson BD, Gao S, Gerik J, et al. 2013. Preplant 1,3-D treatments test well for perennial crop nurseries, but challenges remain. Calif Agr 67(3):181-9.

Jhala AJ, Gao S, Gerik JS, et al. 2012. Effects of surface treatments and application shanks on nematode, pathogen and weed control with 1,3-dichloropropene. Pest Manag Sci 68:225-30
Oin R, Gao S, Ajwa H, et al. 2011. Field evaluation of a new plastic film (VaporSafe) to reduce fumigant emis sions and improve distribution in soil. J Environ Qual 40:1195-203.

[US EPA] US Environmental Protection Agency. 2009. Implementation of Risk Mitigation Measures for Soil Fumigant Pesticides. www.epa.gov/oppsrrd1/reregistration/soil_fumigants/\#ammendedreds. 